\title{
The Transmembrane pH Gradient Drives Uphill Folate Transport in Rabbit Jejunum

\author{
Direct Evidence for Folate/Hydroxyl Exchange in Brush Border Membrane Vesicles
}

Charles M. Schron, Clarence Washington, Jr., and Bennett L. Blitzer

Division of Digestive Diseases and Liver Study Unit, Department of Internal Medicine, University of Cincinnati College of Medicine, Cincinnati, Ohio 45267

\section{Abstract}

In rabbit jejunal, but not ileal brush border membrane vesicles, an outwardly directed $\mathrm{OH}^{-}$gradient (pH 7.7 inside, pH 5.5 outside) markedly stimulated the initial velocity of folate $(0.1 \mu \mathrm{M})$ uptake compared with uptake in the absence of a $\mathrm{pH}$ gradient. Under pH gradient conditions, folate was transiently accumulated at a concentration four times that found at equilibrium (overshoot), implying uphill transport of the vitamin. Equilibrium folate uptake was inversely proportional to medium osmolality, suggesting uptake into an osmotically sensitive space. pH gradient-stimulated folate uptake was markedly reduced by inhibitors of anion exchange (4,4'-diisothiocyano-2,2'-disulfonic acid stilbene; 4-acetamido-4-isothiocyanostilbene-2,2'-disulfonic acid; furosemide), and was saturable (folate $K_{\mathrm{m}}=0.19 \pm 0.02 \mu \mathrm{M}$; $V_{\max }=12.8 \pm 0.4 \mathrm{pmol} \cdot \mathrm{mg}$ protein $\left.{ }^{-1} \cdot \mathrm{min}^{-1}\right)$. Imposition of an inside-positive electrical potential did not stimulate folate uptake, suggesting that stimulation by a pH gradient was not due to an induced electrical potential. In contrast, an inwardly directed $\mathrm{Na}^{+}$or $\mathrm{K}^{+}$gradient did not stimulate folate uptake.

These findings provide evidence for a carrier on the jejunal brush border membrane that mediates folate $/ \mathrm{OH}^{-}$exchange (or $\mathrm{H}^{+}$/folate co-transport), and are consonant with the known presence of an outwardly directed $\mathrm{OH}^{-}$gradient in vivo (brush border acid microclimate), an acidic pH optimum for intestinal folate uptake, and the primary role of the jejunum in folate absorption.

\section{Introduction}

Dietary folate, pteroylpolyglutamic acid, is hydrolyzed at the intestinal brush border to the monoglutamyl form and the anionic moiety is subsequently absorbed predominantly in the jejunum by an energy dependent, saturable process. This process is competitively inhibited by folate analogues and is maximal at a luminal $\mathrm{pH}$ between 5.5 and $6.0(1,2)$. These findings suggest a brush border, carrier-mediated mechanism for intestinal folate transport.

Portions of this work were presented at the annual meeting of the American Gastroenterological Association (1985. Gastroenterology. 88:1576).

Address reprint and correspondence requests to Dr. Schron.

Received for publication 18 July 1985.

J. Clin. Invest.

(c) The American Society for Clinical Investigation, Inc.

$0021-9738 / 85 / 11 / 2030 / 04 \$ 1.00$

Volume 76, November 1985, 2030-2033
A previous study in rat intestinal brush border membrane $(B B M)^{1}$ vesicles confirmed these earlier findings and identified an acidic $\mathrm{pH}$ optimum for carrier-mediated folate transport (3). However, folate uptake was not examined under $\mathrm{pH}$ gradient conditions, and uphill transport of folate against an electrochemical gradient was not demonstrated. Therefore, the driving forces for folate transport were not defined.

Since, in the leukemic cell line L1210, an anion exchange mechanism mediates the transport of folate (4), a similar mechanism may be operative in the intestine. Moreover, $\mathrm{pH}$ gradient dependent, anion exchange mechanisms for the transport of $\mathrm{Cl}^{-}$ (5), $\mathrm{SO}_{4}{ }^{-2}(6)$, and oxalate (7) have recently been identified in rat and rabbit ileal $\mathrm{BBM}$ vesicles. In the present study, the effect of the transmembrane $\mathrm{pH}$ gradient on folate uptake by rabbit intestinal BBM vesicles was assessed in order to elucidate the driving forces for uphill transport of the vitamin.

\section{Methods}

Preparation of BBM vesicles. Rabbit jejunal BBM vesicles were prepared by a divalent cation precipitation method as previously described (8). Briefly, fed New Zealand white male rabbits were killed by air embolus and the first four feet of small intestine beginning $8 \mathrm{~cm}$ distal to the pylorus were removed. Mucosal scrapings were combined with buffer $A$ (10 mM Tris, $16 \mathrm{mM}$ Hepes, $300 \mathrm{mM}$ mannitol; $\mathrm{pH} 7.5$ ) in a ratio of one part buffer $A$ to three parts mucosal scrapings (vol/wt), homogenized, and subcellular fractionation was carried out as previously described (8). The final pellet was suspended in buffer A (40-60 mg protein $/ \mathrm{ml}$ ), and transport experiments were performed on the day of preparation.

Since this method had previously been validated only for the preparation of ileal BBM vesicles (8), the purity of jejunal BBM vesicles was assessed by measuring activities of various enzyme markers of the plasma membrane and subcellular organelles. In jejunal vesicles, the activity of lactase (9), a BBM marker enzyme, was enriched 12.6-fold compared with homogenate $(5.67 \pm 0.54$ vs. $0.48 \pm 0.04 \mu \mathrm{g}$ glucose $\cdot \mathrm{mg}$ pro$\left.\operatorname{tein}^{-1} \cdot \min ^{-1}[n=11]\right)$. In contrast, the activities of $\mathrm{Na}^{+}, \mathrm{K}^{+}$-ATPase (basolateral membrane [10]), succinate cytochrome $c$ reductase (mitochondrial [11]), and NADPH cytochrome $c$ reductase (endoplasmic reticulum [12]) were not enriched in jejunal vesicles compared with homogenate $\left(2.35 \pm 0.57\right.$ vs. $2.52 \pm 0.32 \mu \mathrm{mol} \mathrm{Pi} \cdot \mathrm{mg} \operatorname{protein}^{-1} \cdot \mathrm{h}^{-1}[n=6]$; $0.011 \pm 0.008$ vs. $0.048 \pm 0.002 \mathrm{nmol} \cdot \mathrm{mg}$ protein $-1 \cdot \min ^{-1}[n=3]$; and $14.0 \pm 3.1$ vs. $17.5 \pm 1.2 \mathrm{nmol} \cdot \mathrm{mg}$ protein ${ }^{-1} \cdot \min ^{-1}[n=5]$, respectively). Mean total recoveries of enzyme activities were $92.8 \pm 4.1 \%$ (range 83.8 $100.2 \%)$.

1. Abbreviations used in this paper: BBM, brush border membrane; DIDS, 4,4'-diisothiocyano-2,2'-disulfonic acid stilbene; SITS, 4-acetamido-4isothiocyanostilbene-2,2'-disulfonic acid. 
Vesicle uptake of ${ }^{3} \mathrm{H}$-folate. Vesicle uptake of ${ }^{3} \mathrm{H}$-folate was measured by a rapid Millipore filtration technique (8). After preincubation at room temperature for $2 \mathrm{~h}$, the membrane vesicles $(10 \mu \mathrm{l})$ were added to a reaction mixture $(40 \mu \mathrm{l})$ containing varying concentrations of ${ }^{3} \mathrm{H}$-folate and unlabeled folate, and incubated at $30^{\circ} \mathrm{C}$. Each uptake was terminated by the rapid addition of $3 \mathrm{ml}$ of iced-cold, isotonic stop solution ( $10 \mathrm{mM}$ Tris, $16 \mathrm{mM}$ Hepes, $\mathrm{pH} 7.5 ; 182 \mathrm{mM} \mathrm{K}^{+}$gluconate) and immediate filtration through a $0.45-\mu \mathrm{m}$ Millipore filter (HAWP). The filter was then washed twice with $3 \mathrm{ml}$ of iced-cold stop solution, dissolved in Hydrofluor scintillation cocktail (National Diagnostics Inc., Somerville, NJ), and counted on an LS 6800 liquid scintillation counter (Beckman Instruments Inc., Fullerton, CA).

Uptakes were performed in triplicate on at least three separate membrane preparations and the results expressed as the mean $\pm \mathrm{SE}$ for all membrane preparations tested. Differences among means were tested for statistical significance $(P<0.05)$ using paired $t$ test.

Materials. ${ }^{3} \mathrm{H}$-folate $(28 \mathrm{Ci} / \mathrm{mmol})$ was obtained from Amersham Corp. (Arlington Heights, IL), and unlabeled folic acid was from Sigma Chemical Co. (St. Louis, MO). Furosemide was kindly provided by Hoechst-Roussel Pharmaceuticals (Somerville, NJ), bumetanide by Hoffmann-La Roche Inc. (Nutley, NJ), and amiloride $\mathrm{HCl}$ by Merck, Sharp and Dohme Div., Merck \& Co. Inc. (West Point, PA). Hepes was obtained from United States Biochemical (Cleveland, $\mathrm{OH}$ ); 4-acetamido4-isothiocyanostilbene-2,2'disulfonic acid, disodium salt (SITS) was from ICN Pharmaceutical Inc. (Plainview, NY); and 4,4'-diisothiocyano-2,2'disulfonic acid stilbene, disodium salt (DIDS) was from Sigma Chemical Co. All chemicals were of reagent grade or the highest purity available.

\section{Results}

Effects of transmembrane $\mathrm{pH}$ gradient on folate uptake. In ileal vesicles (Fig. 1), folate uptake under $\mathrm{pH}$ gradient conditions $(\mathrm{pH}$ 7.7 inside the vesicle, $\mathrm{pH} 5.5$ outside the vesicle; open circles) was similar at all time points to uptake in the absence of a $\mathrm{pH}$ gradient ( $\mathrm{pH} 5.5$ inside and outside; open triangles).

In contrast, in jejunal BBM vesicles, the initial velocity of folate $(0.1 \mu \mathrm{M})$ uptake (measured at $6 \mathrm{~s}$ ) was relatively rapid in the presence of an outwardly directed $\mathrm{OH}^{-}$gradient $(\mathrm{pH} 7.7$ inside, pH 5.5 outside; solid circles, Fig. 1). Moreover, at $1 \mathrm{~min}$, folate was transiently accumulated at a concentration four times

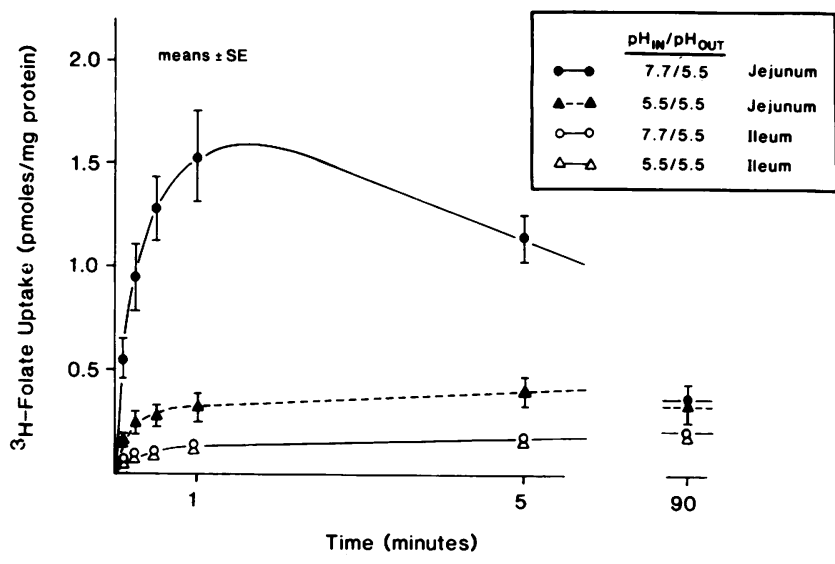

Figure 1. Effect of transmembrane $\mathrm{pH}$ gradient on folate uptake. Ileal $(0, \Delta)$ or jejunal BBM vesicles $(\bullet, \Delta)$ were preloaded with $70 \mathrm{mM}$ Tris, $70 \mathrm{mM}$ Hepes, and $250 \mathrm{mM}$ mannitol, pH 7.7 (circles), or $16 \mathrm{mM}$ Tris, $20 \mathrm{mM}$ Hepes, $104 \mathrm{mM}$ 2-[ $\mathrm{N}$-morpholino]ethanesulfonic acid (MES), and $250 \mathrm{mM}$ mannitol, pH 5.5 (triangles). Uptakes were initiated by adding $10 \mu \mathrm{l}$ of vesicles to $40 \mu \mathrm{l}$ of $\mathrm{pH} 5.5$ buffer containing ${ }^{3} \mathrm{H}$-folate $(0.1 \mu \mathrm{M})$. that found at equilibrium (overshoot), implying uphill transport of the vitamin. In the absence of a pH gradient (solid triangles), jejunal folate uptake was relatively slow (25\% of uptake under pH gradient conditions), and no overshoot was observed. Furthermore, imposition of an inwardly directed $\mathrm{Na}^{+}$or $\mathrm{K}^{+}$gradient (in/out $=0 / 60 \mathrm{mM}$ ) in the absence of a $\mathrm{pH}$ gradient did not stimulate folate $(0.1 \mu \mathrm{M})$ uptake (at $6 \mathrm{~s}$ ) compared with a cationfree control (105 \pm 3 and $108 \pm 3 \%$ of control, respectively [ $n$ $=3]$ ).

Effect of an electrical potential on folate uptake. Since an outwardly directed $\mathrm{OH}^{-}$gradient may generate an inside-positive electrical potential and possibly stimulate uptake of negatively charged folate (electrical coupling), experiments were performed to assess the effects of an electrical potential on folate uptake by jejunal BBM vesicles. An inside-positive electrical potential was established in the absence of a pH gradient ( $\mathrm{pH} 5.5$ in and out) by exposing the vesicles to an inwardly directed $50 \mathrm{mM} \mathrm{K}^{+}$gradient in the presence of the $\mathrm{K}^{+}$ionophore, valinomycin $(10 \mu \mathrm{g} /$ mg protein). Uptake under these conditions was compared with uptake in the absence of an imposed electrical potential $\left(\left[\mathrm{K}^{+}\right]\right.$ in/out $=50 / 50 \mathrm{mM}$ plus valinomycin), i.e., under voltageclamped conditions. Folate uptake was similar in the presence or absence of an inside-positive electrical potential at all time points $\left(0.17 \pm 0.02\right.$ vs. $0.16 \pm 0.01 \mathrm{pmol} \cdot \mathrm{mg}$ protein $^{-1}$ at $15 \mathrm{~s}$; $0.20 \pm 0.02$ vs. $0.19 \pm 0.01$ at $30 \mathrm{~s} ; 0.23 \pm 0.03$ vs. $0.21 \pm 0.02$ at 60 $\mathrm{s}$; and $0.22 \pm 0.04$ vs. $0.21 \pm 0.04$ at $90 \mathrm{~min}$, respectively [ $n=3]$ ). In the presence of an identical inwardly directed $\mathrm{K}^{+}$gradient (plus valinomycin), $\mathrm{Na}^{+}$-stimulated glucose uptake, an electrogenic process, was significantly inhibited, confirming that an inside-positive electrical potential was established under these conditions (data not shown). These data suggest that stimulation of folate uptake by a $\mathrm{pH}$ gradient cannot be due to electrical coupling.

Effect of medium osmolality on jejunal folate uptake. To document uptake of folate into an osmotically sensitive space, medium osmolality was varied using the impermeant solute cellobiose and equilibrium folate uptake was measured. Uptake was inversely proportional to medium osmolality (Fig. 2), suggesting osmotically sensitive transport. The positive y-intercept, representing uptake at infinite osmolality (i.e., intravesicular space $=0$ ), indicates a contribution of binding to total uptake. However, uptake measured at 1.8, 3.0,4.8, and $6.0 \mathrm{~s}$ was linear with time and the regression line passed through the origin (data not shown). This latter observation suggests that binding does not significantly affect the initial velocity of folate uptake. Since uptake was linear through $6 \mathrm{~s}$, uptakes at $6 \mathrm{~s}$ were used to estimate initial rates of folate uptake.

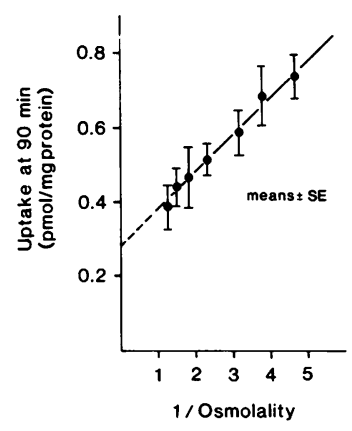

Figure 2. Effect of medium osmolality on equilibrium folate uptake. Jejunal BBM vesicles were loaded with $\mathrm{pH} 5.5$ buffer ( $8 \mathrm{mM}$ Tris, $10 \mathrm{mM}$ Hepes, 52 mM 2-[ $N$-morpholino]ethanesulfonic acid, and $150 \mathrm{mM}$ mannitol) and incubated in a pH 5.5 buffer containing ${ }^{3} \mathrm{H}$-folate $(0.1 \mu \mathrm{M})$ and varying concentrations of cellobiose $(0-500 \mathrm{mM})$. Uptakes were stopped at $90 \mathrm{~min}$ with stop solutions that were isosmotic with the reaction media. The individual data points were fitted to a straight line by linear regression analysis. 
Effects of membrane transport inhibitors. The effects of inhibitors ( $1 \mathrm{mM})$ of membrane transport (13) on $\mathrm{pH}$ gradientstimulated folate uptake were also studied (Fig. 3). DIDS and SITS, inhibitors of erythrocyte and epithelial anion exchange processes, were potent inhibitors of $\mathrm{pH}$ gradient-stimulated folate uptake (84 and $77 \%$ inhibition, respectively). Furosemide, an inhibitor of cotransport $\left(\mathrm{Na}^{+} / \mathrm{Cl}^{-}\right.$and $\left.\mathrm{Na}^{+} / \mathrm{K}^{+} / \mathrm{Cl}^{-}\right)$and of anion exchange, also significantly inhibited folate uptake $(50 \%)$. None of the inhibitors affected equilibrium glucose uptake (data not shown), suggesting that these inhibitors did not adversely affect vesicle integrity. Folate uptake was not significantly affected by bumetanide, amiloride, or harmaline (inhibitors of $\mathrm{Na}^{+} / \mathrm{Cl}^{-}$cotransport, $\mathrm{Na}^{+} / \mathrm{H}^{+}$exchange, and apical $\mathrm{Na}^{+}$transport, respectively).

Kinetics of folate uptake. The kinetics of folate uptake were determined by incubating jejunal BBM vesicles with varying folate concentrations under $\mathrm{pH}$ gradient conditions in the absence or presence of $1 \mathrm{mM}$ DIDS. The DIDS-sensitive component of folate uptake, calculated as the difference between total uptake and uptake in the presence of DIDS, was saturable (Fig. 4). A computer derived (14), weighted least squares fit of the individual data points yielded a rectangular hyperbola and a folate $K_{\mathrm{m}}$ of $0.19 \pm 0.02 \mu \mathrm{M}$ and a $V_{\max }$ of $12.8 \pm 0.4 \mathrm{pmol} \cdot \mathrm{mg}$ protein ${ }^{-1} \cdot \mathrm{min}^{-1}$.

\section{Discussion}

The findings of the present study suggest that the transmembrane $\mathrm{pH}$ gradient drives uphill folate transport by carrier-mediated folate $/ \mathrm{OH}^{-}$exchange. In jejunal BBM vesicles, an outwardly directed $\mathrm{OH}^{-}$gradient stimulates the initial velocity of folate uptake, and the vitamin is transiently accumulated at a concentration four times that found at equilibrium, implying uphill transport. Furthermore, $\mathrm{pH}$ gradient-stimulated folate uptake is markedly reduced by known inhibitors of anion exchange processes (DIDS, SITS, and furosemide). DIDS-sensitive $\mathrm{pH}$ gradient-stimulated folate uptake is saturable with a folate $K_{\mathrm{m}}$ of $0.19 \pm 0.02 \mu \mathrm{M}$ and a $V_{\max }$ of $12.8 \pm 0.4 \mathrm{pmol} \cdot \mathrm{mg}$ pro$\operatorname{tein}^{-1} \cdot \min ^{-1}$. This value for the folate $K_{\mathrm{m}}$ is within an order of magnitude of previously reported values for intact jejunum (1.2$7.2 \mu \mathrm{M}$, reference 2). Finally, folate uptake is not stimulated by

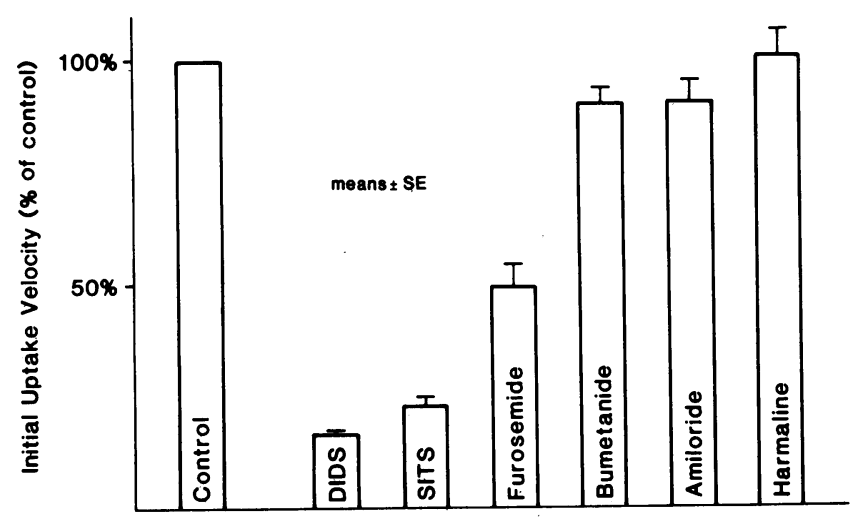

Transport Inhibitors (1 mM)

Figure 3. Effects of transport inhibitors on folate uptake by jejunal BBM vesicles. $\mathrm{pH}$ gradient-stimulated folate uptake ( $\mathrm{pH} 7.7$ inside, pH 5.5 outside) was determined at $6 \mathrm{~s}$ in the presence or absence (control) of $1 \mathrm{mM}$ inhibitor. Buffer composition as in Fig. 1.

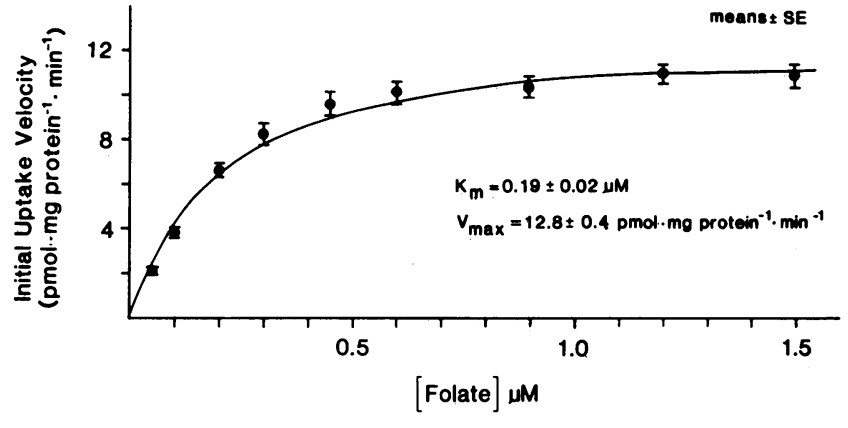

Figure 4. Kinetics of $\mathrm{pH}$ gradient-stimulated folate uptake. Under $\mathrm{pH}$ gradient conditions ( $\mathrm{pH} 7.7$ inside, $\mathrm{pH} 5.5$ outside), folate uptake by jejunal BBM vesicles was determined at $6 \mathrm{~s}$ in the absence or presence of $1 \mathrm{mM}$ DIDS as folate concentration was varied from 0.05 to 1.5 $\mu \mathrm{M}$. The DIDS-sensitive component of folate uptake was calculated as the difference between total uptake and uptake in the presence of DIDS. A weighted, least squares fit of the individual data points was performed on a computer yielding the depicted rectangular hyperbola and kinetic parameters. Symbols depict means \pm SE of individual data points.

an inside-positive electrical potential, thereby excluding electrical coupling as an explanation for $\mathrm{pH}$ gradient-stimulated folate uptake. These results strongly suggest carrier mediated folate/ $\mathrm{OH}^{-}$exchange (or phenomenologically indistinguishable $\mathrm{H}^{+}$/ folate co-transport). Furthermore, a $\mathrm{Na}^{+}$/folate co-transport mechanism is unlikely, since stimulation of folate uptake by a $\mathrm{Na}^{+}$gradient was not observed.

These results differ significantly from those of a preliminary study (15) using rat intestinal BBM vesicles in which uphill folate transport (viz. an overshoot) was not clearly demonstrated and no comparison was made between jejunal and ileal BBM vesicles. Although, in that study, folate transport was enhanced under conditions of an outwardly directed $\mathrm{OH}^{-}$gradient, uptake was also stimulated by an inwardly directed $\mathrm{Na}^{+}$gradient or an inwardly directed $\mathrm{K}^{+}$gradient in the presence of valinomycin. Since the increment in folate uptake under $\mathrm{Na}^{+}$gradient conditions was identical to the stimulation by an inwardly directed $\mathrm{K}^{+}$gradient plus valinomycin, these investigators concluded that electrical coupling could account for $\mathrm{Na}^{+}$gradient-stimulated folate uptake. Similarly, the $\mathrm{pH}$ gradient stimulation might also have been secondary to electrical coupling. The disparate responses of folate uptake to an inside-positive electrical potential in that study compared with those of the present study may have been due to membrane preparation or species differences. In any event, an inside-positive electrical potential is an unlikely driving force for the uphill transport of folate in vivo, since the interior of the enterocyte is normally electrically negative ( -40 $\mathrm{mV}$ relative to lumen) (16).

In contrast, the present findings are consistent with the cardinal features of folate transport by intact intestine. The requirement of an acidic luminal $\mathrm{pH}$ for folate transport (2) was initially thought to imply a $\mathrm{pH}$ optimum for carrier-mediated folate uptake (3), or passive nonionic diffusion (17) of the undissociated acid $\left(\mathrm{pK}_{\mathrm{A}}=3.5\right.$ and 4.8$)$. However, the present study suggests that the transmembrane $\mathrm{pH}$ gradient and not the luminal $\mathrm{pH}$ per se is critically required for intestinal folate absorption. Recordings of the $\mathrm{pH}$ at the luminal surface document a brush border acid microclimate in proximal jejunum (luminal pH 5.8) (17). Since this value is significantly below the $\mathrm{pH}$ of the entero- 
cyte interior $(\sim 6.8$, reference 18$)$, an outwardly directed $\mathrm{OH}^{-}$ gradient is present under physiological conditions. Thus, the outwardly directed $\mathrm{OH}^{-}$gradient required for uphill folate transport by BBM vesicles in vitro is present in vivo. Our finding of folate $/ \mathrm{OH}^{-}$exchange in jejunal, but not ileal BBM vesicles is also consistent with the primacy of the jejunum in folate absorption (2). Finally, the $\mathrm{Na}^{+}$dependence of folate transport observed by others (19) may be secondary to dual exchange, i.e., the parallel operation of carriers mediating $\mathrm{Na}^{+} / \mathrm{H}^{+}(8)$ and folate $/ \mathrm{OH}^{-}$exchange.

In summary, the present study provides evidence for a carrier on the jejunal brush border membrane that mediates folate/ $\mathrm{OH}^{-}$exchange (or $\mathrm{H}^{+}$/folate co-transport) and is consonant with the known presence of an outwardly directed $\mathrm{OH}^{-}$gradient in vivo (acid microclimate), an acidic $\mathrm{pH}$ optimum for intestinal folate transport and the primary role of the jejunum in folate absorption. Furthermore, these studies suggest that the transmembrane $\mathrm{pH}$ gradient drives uphill transport of folate under physiological conditions.

\section{Acknowledgments}

This work was supported by a University of Cincinnati Clinical Teaching Subsidy (to Dr. Schron), U. S. Public Health Service grant AM-31205 (to Dr. Blitzer), and by gifts to the Justin J. Stevenson, Jr. Liver Research Laboratory.

\section{References}

1. Steinberg, S. E. 1984. Mechanisms of folate homeostasis. Am. J. Physiol. 246:G319-G324.

2. Rosenberg, I. H. 1981. Intestinal absorption of folate. In Physiology of the Gastrointestinal Tract. L. R. Johnson, editor. Raven Press, New York. 1221-1230.

3. Selhub, J., and I. H. Rosenberg. 1981. Folate transport in isolated brush border membrane vesicles from rat intestine. J. Biol. Chem. 256: 4489-4493.

4. Yang, C. H., F. M. Sirotnak, and M. Dembo. 1984. Interaction between anions and the reduced folate/methotrexate transport system in L1210 cell plasma membrane vesicles: directional symmetry and anion specificity for differential mobility of loaded and unloaded carrier. $J$. Membr. Biol. 79:285-292.
5. Liedtke, C. M., and U. Hopfer. 1982، Mechanism of $\mathrm{Cl}^{-}$translocation across small intestinal brush-border membrane. II. Demonstration of $\mathrm{Cl}^{-}-\mathrm{OH}^{-}$exchange and $\mathrm{Cl}^{-}$conductance. Am. J. Physiol. 242: G272-G280.

6. Schron, C. M., R. G. Knickelbein, P. S. Aronson, and J. W. Dobbins. 1984. $\mathrm{SO}_{4}: \mathrm{OH}$ exchange on brush border vesicles from rabbit ileum. Fed. Proc. 43:299a. (Abstr.)

7. Knickelbein, R. G., C. M. Schron, P. S. Aronson, and J. W. Dobbins. 1985. Anion exchange across rabbit ileal brush border membrane (BBM). Gastroenterology. 88:1449a. (Abstr.)

8. Knickelbein, R. G., P. S. Aronson, W. Atherton, and J. W. Dobbins. 1983. Sodium and chloride transport across rabbit ileal brush border. I. Evidence for Na-H exchange. Am. J. Physiol. 245:G504-G510.

9. Dahlquist, A. 1964. Method for assay of intestinal disaccharidases. Anal. Biochem. 7:18-25.

10. Scharschmidt, B. F., E. B. Keeffe, N. M. Blankenship, and R. K. Ockner. 1979. Validation of a recording spectrophotometric method for measurement of membrane-associated $\mathrm{Mg}$ and $\mathrm{Na} / \mathrm{K}$ ATPase activity. J. Lab. Clin. Med. 93:790-799.

11. Tisdale, H. D. 1967. Preparation and properties of succinic-cytochrome c reductase (complex II-III). Methods Enzymol. 10:213-215.

12. Sottocasa, G. L., B. Kuylenstierna, L. Ernster, and A. Bergstrand. 1967. An electron-transport system associated with the outer membrane of liver mitochondria. J. Cell Biol. 32:415-438.

13. Aronson, P. S. 1981. Identifying secondary active solute transport in epithelia. Am. J. Physiol. 240:F1-F11.

14. Cleland, W. 1979. Statistical analysis of enzyme kinetic data. Methods Enzymol. 63:103-138.

15. Selhub, J., R. Arnold, and I. H. Rosenberg. 1984. Mechanism of $\mathrm{Na}^{+}$and $\mathrm{H}^{+}$effects on folate transport by brush border membrane (BBM) vesicles from rat intestine. Gástroenterology. 86:1243a. (Abstr.)

16. Schultz, S. G. 1981. Salt and water absorption by mammalian small intestine. In Physiology of the Gastrointestinal Tract. L. R. Johnson, editor. Raven Press, New York. 983-989.

17. Lucas, M. L., and J. A. Blair. 1978. The magnitude and distribution of the acid microclimate in proximal jejunum and its relation to luminal acidification. Proc. R. Soc. Lond. A. 200:27-41.

18. Kurtin, P., and A. N. Charney. 1984. Intestinal ion transport and intracellular $\mathrm{pH}$ during acute respiratory alkalosis and acidosis. $\mathrm{Am}$. J. Physiol. 247:G24-G31.

19. Eilam, Y., M. Ariel, M. Jablonska, and N. Grossowicz. 1981. On the mechanism of folate transport in isolated intestinal epithelial cells. Am. J. Physiol. 240:G170-G175. 